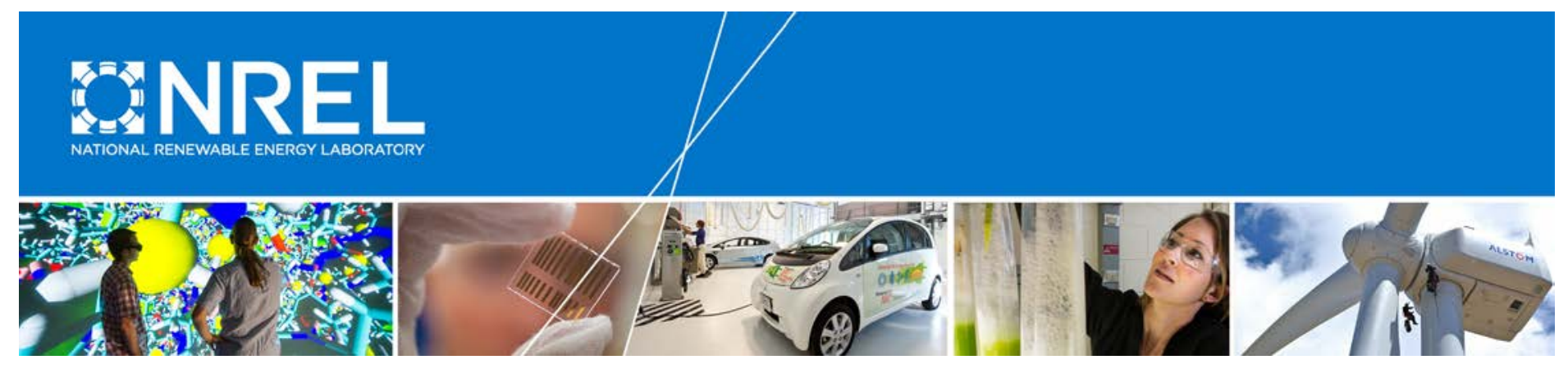

\title{
Electrical Power Conversion of a River and Tidal Power Generator
}

\section{Preprint}

Eduard Muljadi, Vahan Gevorgian, and Alan Wright

National Renewable Energy Laboratory

James Donegan, Cian Marnagh, and Jarlath McEntee

Ocean Renewable Power Company

To be presented at the 2016 IEEE North American Power

Symposium

Denver, Colorado

September 18-20, 2016

(C) 2016 IEEE. Personal use of this material is permitted. Permission from IEEE must be obtained for all other uses, in any current or future media, including reprinting/republishing this material for advertising or promotional purposes, creating new collective works, for resale or redistribution to servers or lists, or reuse of any copyrighted component of this work in other works.

NREL is a national laboratory of the U.S. Department of Energy Office of Energy Efficiency \& Renewable Energy Operated by the Alliance for Sustainable Energy, LLC

This report is available at no cost from the National Renewable Energy Laboratory (NREL) at www.nrel.gov/publications.

Conference Paper

NREL/CP-5D00-66866

September 2016

Contract No. DE-AC36-08GO28308 


\section{NOTICE}

The submitted manuscript has been offered by an employee of the Alliance for Sustainable Energy, LLC (Alliance), a contractor of the US Government under Contract No. DE-AC36-08GO28308. Accordingly, the US Government and Alliance retain a nonexclusive royalty-free license to publish or reproduce the published form of this contribution, or allow others to do so, for US Government purposes.

This report was prepared as an account of work sponsored by an agency of the United States government. Neither the United States government nor any agency thereof, nor any of their employees, makes any warranty, express or implied, or assumes any legal liability or responsibility for the accuracy, completeness, or usefulness of any information, apparatus, product, or process disclosed, or represents that its use would not infringe privately owned rights. Reference herein to any specific commercial product, process, or service by trade name, trademark, manufacturer, or otherwise does not necessarily constitute or imply its endorsement, recommendation, or favoring by the United States government or any agency thereof. The views and opinions of authors expressed herein do not necessarily state or reflect those of the United States government or any agency thereof.

This report is available at no cost from the National Renewable Energy Laboratory (NREL) at www.nrel.gov/publications.

Available electronically at SciTech Connect http:/www.osti.gov/scitech

Available for a processing fee to U.S. Department of Energy and its contractors, in paper, from:

U.S. Department of Energy

Office of Scientific and Technical Information

P.O. Box 62

Oak Ridge, TN 37831-0062

OSTI http://www.osti.gov

Phone: 865.576.8401

Fax: 865.576.5728

Email: reports@osti.gov

Available for sale to the public, in paper, from:

U.S. Department of Commerce

National Technical Information Service

5301 Shawnee Road

Alexandria, VA 22312

NTIS http://www.ntis.gov

Phone: 800.553 .6847 or 703.605 .6000

Fax: 703.605.6900

Email: orders@ntis.gov 


\title{
Electrical Power Conversion of a River and Tidal Power Generator
}

\author{
E. Muljadi, V. Gevorgian, A. Wright, J. Donegan, C. Marnagh, J. McEntee
}

\begin{abstract}
As renewable generation has become less expensive during recent decades, and it becomes more accepted by the global population, the focus on renewable generation has expanded to include new types with promising future applications, such as river and tidal generation.

Although the utilization of power electronics and electric machines in industry is phenomenal, the emphasis on system design is different for various sectors of industry. In precision control, robotics, and weaponry, the design emphasis is on accuracy and reliability with less concern for the cost of the final product. In energy generation, the cost of energy is the prime concern; thus, capital expenditures (CAPEX) and operations and maintenance expenditures (OPEX) are the major design objectives.

This paper describes the electrical power conversion aspects of river and tidal generation. Although modern power converter control is available to control the generation side, the design was chosen on the bases of minimizing the CAPEX and OPEX; thus, the architecture is simple and modular for ease of replacement and maintenance. The power conversion is simplified by considering a simple diode bridge and a DC-DC power converter to take advantage of abundant and low-cost photovoltaic inverters that have well-proven grid integration characteristics (i.e., the capability to produce energy with good power quality and control real power and voltage on the grid side).
\end{abstract}

Index Terms - ocean power, marine, hydrokinetic, tidal, river, renewable, water power, variable generation, distributed generation.

\section{INTRODUCTION}

$\mathrm{T}$ HIS work is based on a hydrokinetic power generating system for river and tidal generators. The analysis is based on a tentative tidal generator with the power rating of $40 \mathrm{~kW}$, although the same generator can be operated as a river generator. From the resource perspective, tidal generation is dependent on the resource availability; thus, the resource must be identified by preliminary assessment and survey [1]. One difference between a tidal generator and a river generator is the water flow driving each turbine. In river generation, the water flows in one direction and is more or less constant. In tidal generation, the water flows in two directions: during the flood, the water flows from the ocean toward the land or river; during the ebb, the water flows back toward the ocean. There are various ways to harness tidal generation, either from a single turbine [2-3], a combination of wind generators and tidal generators [4], or in a multiple-turbine or tidal power plant environment [5]. Each site has its own characteristics; thus, control and optimization may be unique for different installations [6-8].

In 2014, renewable energy expanded significantly in terms of capacity installed and energy produced, with renewable energy investments in the power sector outpacing net investments in fossil-fueled power plants. The most rapid growth and the largest increase in renewable capacity occurred in the power sector and was dominated by three technologies: wind, solar photovoltaic (PV), and hydropower.

This paper describes the electrical power conversion aspects of river and tidal generation. Although modern power converter control is available to control the generation side, we choose the design on the basis of minimizing the capital expenditures and operations and maintenance expenditures; thus, the architecture is relatively simple and modular for ease of replacement and maintenance. The power conversion is simplified by considering a simple diode bridge and a DC-DC power converter to take advantage of abundant and low-cost PV inverters that have well-proven grid integration characteristics (i.e., the capability to produce energy with good power quality and control real power and voltage at the grid side).

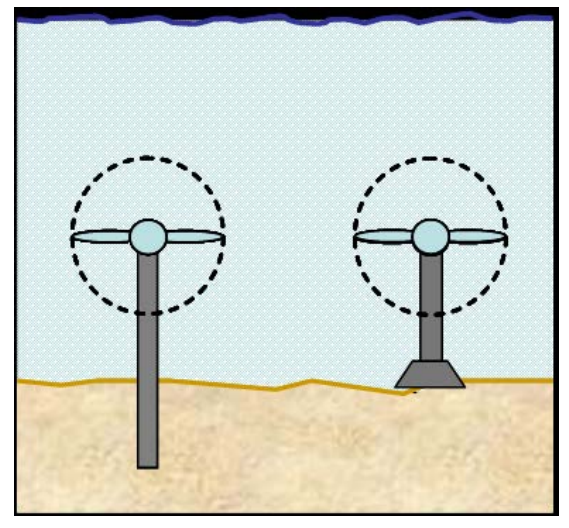

Fig. 1. Typical bottom-mounted tidal generator (source Wikipedia)

A typical tidal generator can be mounted on the bottom of an estuary, and its shape and structure are similar to that of the wind turbine generator as shown in the Figure 1. The Savonius turbine type is also used as the river and tidal generators. It may be placed vertically or horizontally depending on the characteristics of the resource and the site.

This paper is arranged as follows. Section II discusses the electrical power conversion. The permanent magnet generator is presented in Section III, followed by the power converters in Section IV. Finally, Section V presents the conclusion and summary.

\section{SYSTEM-LEVEL DESCRIPTION}

The electrical power conversion in tidal generation is very similar to the generating system of wind power generation. It consists of major components: a rectifier (variable AC to DC 
converter) and an inverter (DC to $\mathrm{AC} 60-\mathrm{Hz}$ converter). Depending on the generator type, the rectifier can be a passive rectifier [9] or an active rectifier [10]. For this discussion, we assume that the system described in this paper is based on a passive rectifier. Thus, a DC-DC converter is used to match and maintain the DC bus voltage constant. With an active rectifier, it is possible to control the DC bus voltage by utilizing the active rectifier alone. This section presents the electrical power conversion. The maximum power point tracker (MPPT) is similar to the one used in wind power generation, however, the implementation is determined by the shape of the performance coefficient $(\mathrm{Cp})$ characteristic $(\mathrm{Cp}$ versus tip-speed-ratio). Detail discussion can be found in [11].

A river and tidal generator using a permanent magnet synchronous generator (PMSG) is investigated. A PMSG has the advantage of higher efficiency and reliability. Because of its lack of a field winding and the nature of variable generation, the PMSG is typically controlled by a series of power converters to produce power for the grid. As shown in Figure 2, the major conversion processes are as follows:

- Hydrodynamic power is converted into electrical power (tidal turbine and PMSG).

- The variable AC (three-phase) output of the PMSG is converted into variable DC voltage (three-phase diode bridge) via a long submarine cable.

- The variable DC output voltage of the diode bridge is connected to a DC-DC boost converter. The output of the DC-DC boost converter is a constant DC bus.

- The constant DC bus voltage is converted into three-phase $\mathrm{AC}$ at $60 \mathrm{~Hz}$ (the inverter is controlled to optimize tidal generation).

The simplified electrical system is illustrated in Figure 3.

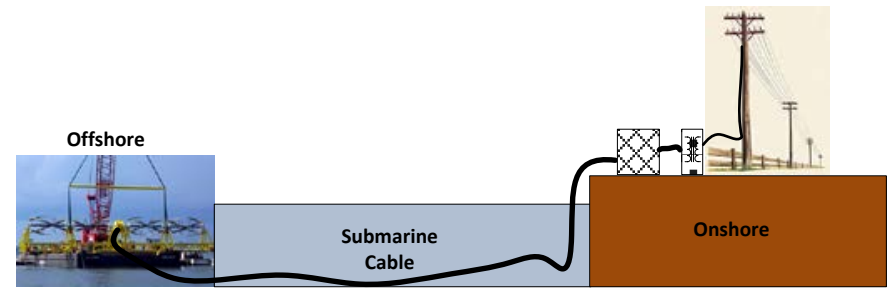

Fig. 2. Typical system of tidal generation

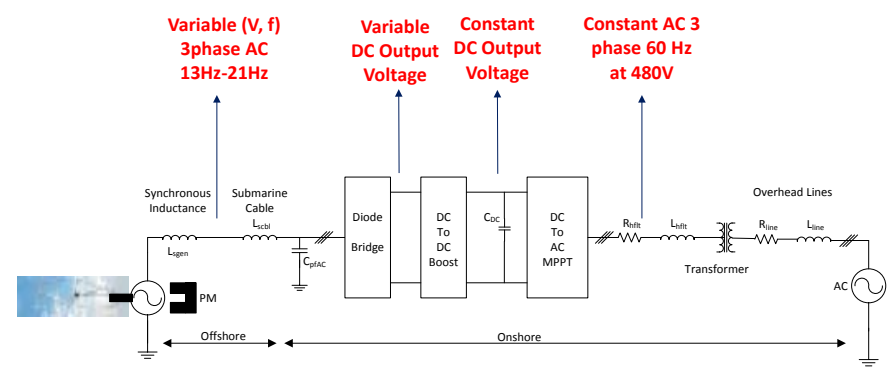

Fig. 3. Single-line diagram of interconnected converters

\section{Permanent Magnet SynChronous Generator}

The PMSG is very popular in variable generation applications. Many of these applications are based on directdrive generators that use rare-earth permanent magnets (PM). The advantage of rare-earth PMs is that the residual flux density is very high, commonly B $=1.4$ Tesla or higher. In comparison, the commonly used PM in the past has been the ferrite magnet, which has a low flux density, $\mathrm{B}=0.4$ Tesla or lower.

A high flux density magnet is very important because, for the same power rating and rotational speeds, the higher the flux density, the smaller and lighter the generator will be. It is assumed that the PM generator used is surface mounted. The equivalent circuit of a PM generator is shown in Figure 4.

\section{A. PMSG Connected to a Constant DC Bus via a Rectifier}

In this section, the PMSG is connected to a constant DC bus voltage via a three-phase rectifier. The simplified version of a surface-mounted PMSG is used.

\section{1) Operation at Constant Frequency}

Consider a constant frequency application, wherein the PMSG is operated at constant rotational speed. In this case, the output voltage, $\mathrm{E}$, is constant because both the magnetic flux and the rotational speed are constant.

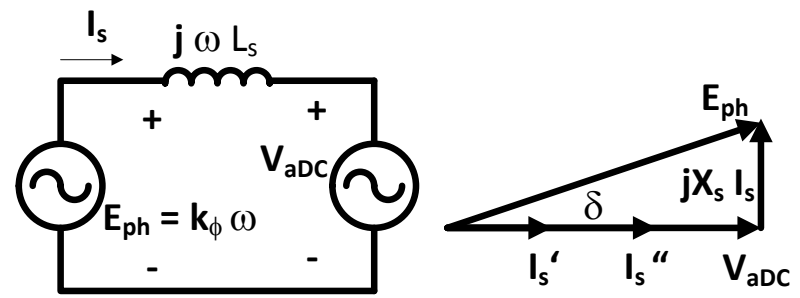

(a) Constant frequency

(b) Phasor diagram representation

Fig. 4. Per-phase equivalent circuit of a PMSG

Because the flux and the frequency (rotational speed) are constant, for a given size of synchronous inductance, $\mathrm{L}_{\mathrm{s}}$, only one output current $\left(\mathrm{I}_{\mathrm{s}}{ }^{\prime}\right)$ and one output power $\left(\mathrm{P}_{\mathrm{s}}{ }^{\prime}\right)$ are associated with this operation (single-point operation). However, if the size of the synchronous inductance is $50 \%$ of the original, the resulting current $\left(\mathrm{I}_{\mathrm{s}}{ }^{\prime \prime}\right)$ and output power $\left(\mathrm{P}_{\mathrm{s}}{ }^{\prime \prime}\right)$ will be twice the original.

$$
\begin{gathered}
V_{a D C}=\frac{\pi}{3 \sqrt{6}} V_{D C} \\
E_{p h}=k_{\Phi} \omega
\end{gathered}
$$

In this case, the constant $k_{\phi}$ is a voltage constant determined by the flux density, and the number of turns, and the geometry of the generator. The voltage equation can be expressed as

$$
E_{p h}=V_{a D C}+j \omega L_{s} I_{s}
$$

$\mathrm{V}_{\mathrm{a} D C}=\mathrm{AC}$ equivalent of per-phase terminal voltage $V_{D C}=D C$ voltage output of the three-phase rectifier

(The rectifier is connected to the terminal of the generator). 
$\mathrm{E}_{\mathrm{ph}}=$ per-phase internal emf

$\mathrm{I}_{\mathrm{s}} \quad=$ stator current

$\mathrm{L}_{\mathrm{s}} \quad=$ stator inductance

$\omega=$ rotational speed in $\mathrm{radian} / \mathrm{s}$

Because the terminal output of the generator is connected to a three-phase rectifier, the per-phase terminal voltage and the stator current are in phase. At this point, assume that the terminal voltage is connected to a rectifier and that the output of the rectifier is a constant $\mathrm{DC}$ bus voltage. Thus, the AC equivalent of the terminal voltage is clamped to this $\mathrm{DC}$ bus voltage.

$$
I_{s}=\frac{\sqrt{E_{p h}^{2}-V_{a D C}^{2}}}{\omega L_{s}}
$$

The per-phase output power can be expressed as

$$
P_{g e n}=V_{a D C} I_{s}
$$

Referring to the phasor diagram in Figure 4, the $\mathrm{V}_{\mathrm{aDC}}$ can be replaced by $\mathrm{E}_{\mathrm{ph}} \cos (\delta)$. By substitution, the output power can also be expressed as

$$
P_{g e n}=\frac{E_{p h}{ }^{2} \sin 2 \delta}{2 \omega L_{s}}=\frac{k_{\Phi}{ }^{2} \omega \sin 2 \delta}{2 L_{s}}
$$

The power angle, $\delta$, is the angle between the per-phase internal emf voltage, $\mathrm{E}_{\mathrm{ph}}$, and the per-phase terminal voltage, $\mathrm{V}_{\mathrm{aDC}}$. It can be computed as

$$
\delta=\operatorname{acos}\left(\frac{V_{a D C}}{E_{p h}}\right)
$$

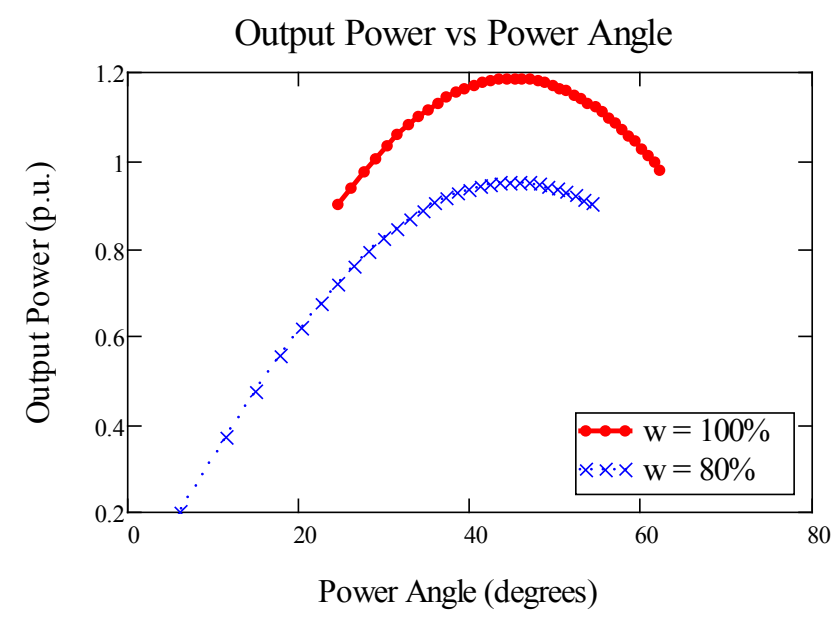

Fig. 5. Output power of a PMSG connected to a rectifier operated at a constant frequency

For operation at a constant frequency, a synchronous generator is connected to a fixed-voltage DC bus via a three-phase rectifier; it has a peak value at $\delta=45^{\circ}$. This is different from a conventional synchronous generator, which has a peak value at $\delta=90^{\circ}$. In Figure 5, as predicted by equation 6 , the operation at a lower frequency will have a lower peak value proportional to the frequency. Referring to Figure 5 and the phasor diagram given in Figure 4, we can say that as we increase the current, $I_{s}$, the voltage drop, $X_{s} I_{s}$, increases, and the voltage $\mathrm{V}_{\mathrm{aDC}}$ decreases. However, because the power is defined by both the current, $\mathrm{I}_{\mathrm{s}}$, and the voltage, $\mathrm{V}_{\mathrm{aDC}}$, eventually, the product of the two reaches a peak value where an additional increase of $I_{s}$ no longer brings the output power up because of the decrease of the voltage, $\mathrm{V}_{\mathrm{aDC}}$, and passing this point, another increase of $I_{s}$ will reduce the output power. This point is reached when the power angle, $\delta$, is at $45^{\circ}$ for the configuration we analyzed.

\section{2) Operation in Variable Frequency}

Consider a variable-frequency application, wherein the PMSG is operated at variable speed. In this case, the internal emf voltage, $\mathrm{E}_{\mathrm{ph}}$, varies with rotational speed because the magnetic flux of the permanent magnet is constant and the rotational speed varies. For PMSG operation, the frequency output is proportional to the operating speed by the following equation:

$$
\begin{aligned}
& \text { rpm }=\frac{120 f}{\text { poles }} \\
& \omega=\frac{r p m(2 \pi)}{60 \mathrm{sec}}
\end{aligned}
$$

From the voltage equations, it is clear that as the rotational speed, $\omega$, increases, and the $\mathrm{E}_{\mathrm{ph}}$ increases while $\mathrm{V}_{\mathrm{aDC}}$ is constant. As a result, when $\mathrm{E}_{\mathrm{ph}}>\mathrm{V}_{\mathrm{aDC}}$, the generator starts to generate. The output current, $\mathrm{I}_{\mathrm{s}}$; the output power, $\mathrm{P}_{\text {gen }}$; and the power angle, $\delta$, also increase.

\section{Emf and Terminal Voltage vs Speed}

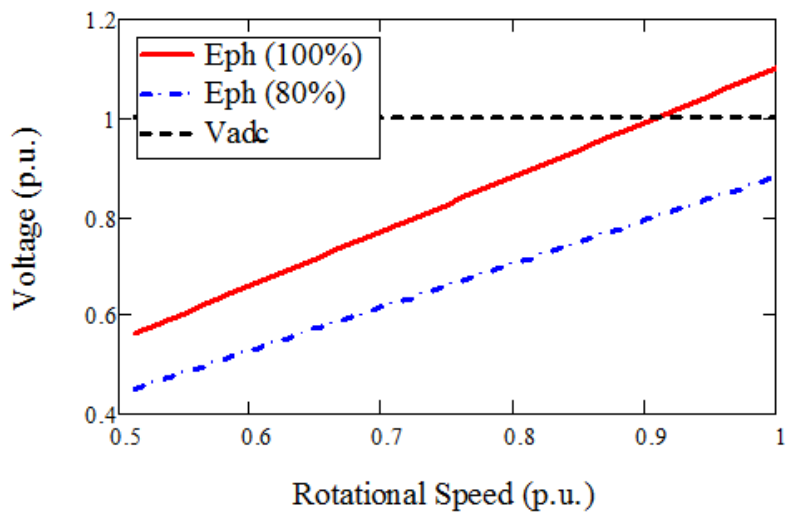

Fig. 6. Per-phase internal voltage, $\mathrm{E}_{\mathrm{ph}}$, and $\mathrm{V}_{\mathrm{aDC}}$

The calculations in this section are given per unit to make them easier to analyze. The generator under consideration starts to generate output power when $E_{p h}$ exceeds the output terminal voltage, $\mathrm{V}_{\mathrm{aDC}}$, at $\omega=0.91$ p.u. (see Figure 6). Note that the blue dashed-dotted line illustrates a condition when the generator used can generate only $80 \%$ or the internal voltage. In this situation, the generator can never generate power, even at rated rotational speed.

The corresponding output power is given in Figure 7. The rotational speed is obtained by operating the synchronous generator by varying the rotational speed (variable frequency) with a constant DC bus voltage. As shown, the output power 
cannot be shaped; it is based on the parameters of the PMSG and the DC bus voltage to which it is connected.

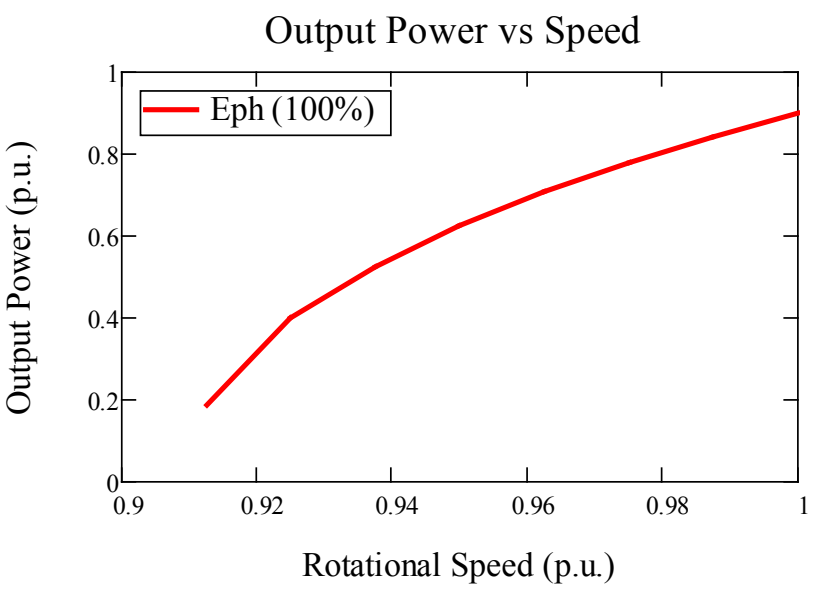

Fig. 7. Output power as a function of rotational speed

\section{3) Operation in Variable DC Bus Voltage}

As shown in Figure 8, operating at constant frequency and constant DC bus voltage will yield a single point of operation; and operating at variable speed will yield a set of points of operation, but the output power cannot be shaped as a function of the rotational speed. One more variable that can be used to shape the power-speed characteristic is to control the effective DC bus voltage connected to the output of the rectifier as the rotational speed varies.

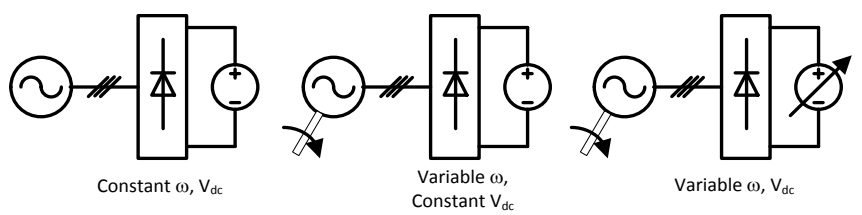

Fig. 8. Three modes of operation

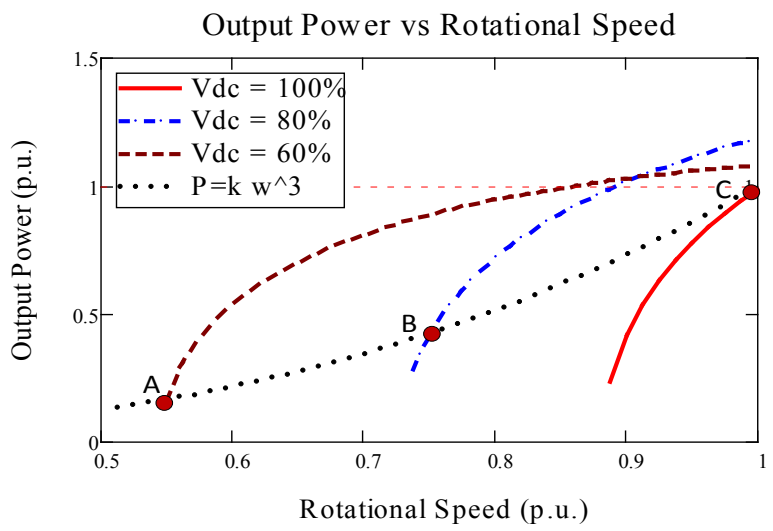

Fig. 9. Operation at variable speed and variable voltage, $V_{d c}$

The operation at variable speed and variable DC bus voltage is illustrated in Figure 9. It is shown that the powerspeed characteristic of the PMSG connected to a rectifier can be shaped by controlling the DC bus as the rotational speed changes. Thus, in this case, the DC bus voltage is controlled to follow the cube function of the rotational speed (the dotted line). To operate along the dotted line, the DC bus voltage can be controlled accordingly. For example, to operate at Point A, the DC bus voltage is at $60 \%$ of its original value. As the rotational speed increases, the operating point moves to Point $\mathrm{B}$, and the DC bus voltage is at $80 \%$. At Point $\mathrm{C}$, the DC bus voltage is at $100 \%$.

\section{POWER CONVERTERS}

In this type of generation, the output of the PMSG driven by the water turbine generates variable frequency proportional to the rotational speed of the turbine, and the process of converting the output power of the PMSG requires a set of power converters necessary to transmit the power into the power grid.

\section{1) $A C-D C$ Rectifier}

The first set of power converters is the AC-DC rectifier, which can be an active power rectifier or a passive diode bridge. Because the PMSG used is connected to the water turbine, the operating speed varies with the water flow. The internal emf voltage, $\mathrm{E}_{\mathrm{ph}}$, and the output voltage magnitude and frequency are proportional to the operating rotational speed. With an active rectifier, the output of the PMSG can be directly converted into a constant DC bus voltage.

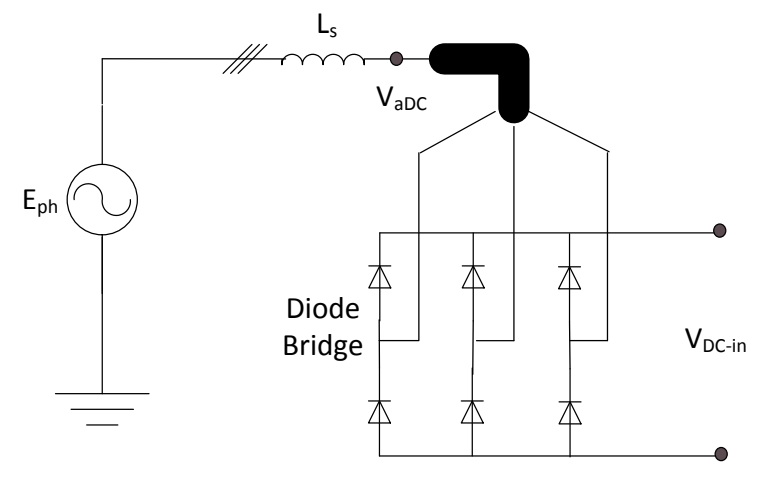

Fig. 10. Operation at variable speed and variable voltage $V_{d c}$

With a passive diode bridge, as shown in Figure 10, the output DC voltage is proportional to the rotational speed if the generator. The following equations can be used to describe the relationship between the PMSG output and the output on the DC bus voltage:

$$
\begin{gathered}
V_{D C-i n}=\frac{3 \sqrt{6}}{\pi} V_{a D C} \\
V_{a D C}=k_{\Phi} \omega-j \omega L_{S} I_{S}
\end{gathered}
$$

\section{2) DC-DC Converter}

The output of the diode rectifier is a variable DC bus voltage; thus, before it is connected to a DC-AC inverter, the DC bus voltage needs to be matched to the required DC bus voltage of the inverter. A DC-DC converter is used to match the DC bus requirement.

To match the variable voltage output of the generator and to shape the power-speed characteristic, a DC-DC boost converter is used (see Figure 11). The corresponding controller is shown in Figure 12. The boost converter is controlled to adjust the voltage output of the diode bridge to a 
constant DC bus voltage as the rotational speed of the PMSG varies.

The operation of the boost converter is governed by the power electronics switch, $\mathrm{SW}_{\text {boost }}$. The power electronics switch is turned on and off many cycles per second (e.g., switch frequency, $f_{s}=1,000 \mathrm{~Hz}$ ). The time it takes to complete one cycle is called the switching period, $\mathrm{T}_{\mathrm{s}}=1 / \mathrm{f}_{\mathrm{s}}$ (e.g., $\mathrm{T}_{\mathrm{s}}=1 \mathrm{~s}$ ). The ratio of the time the switch, $\mathrm{SW}_{\text {boost }}$ is on to the switching period is called the duty ratio.

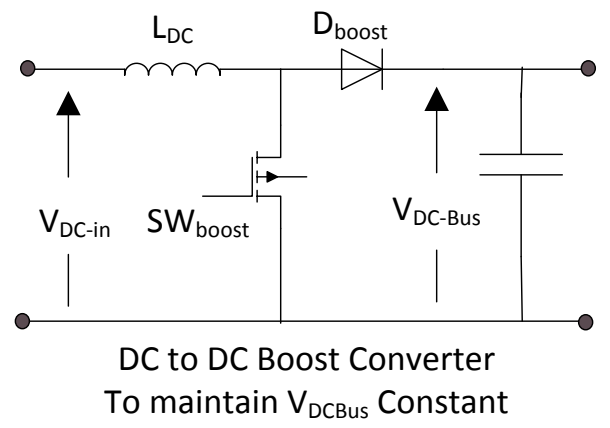

Fig. 11. DC-DC boost converter used to match the output DC voltage of the diode bridge to the constant input voltage of the DC-AC inverter

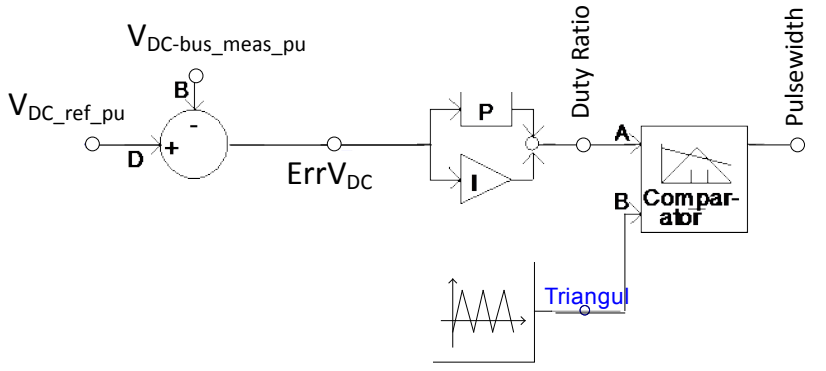

Fig. 12. Typical controller used to control the power switch $\left(\mathrm{SW}_{\text {boost }}\right)$ for the boost DC-DC converter

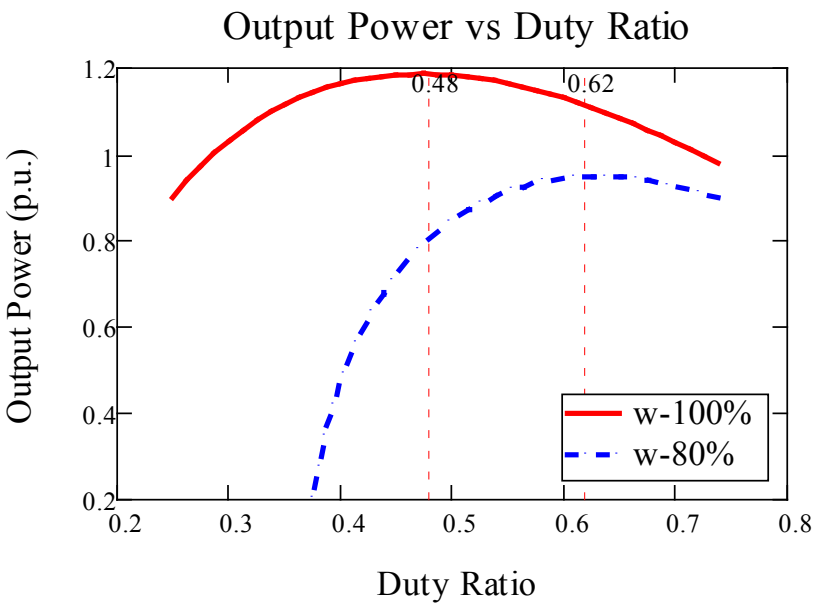

Fig. 13. Output power of the DC-DC boost converter as a function of the duty ratio

Figure 13 shows the output power as a function of the duty ratio when the rotational speed is kept constant. This is similar to the graph shown in Figure 5, except that the output power is plotted against the power angle. Note that the peak power, which corresponds to the power angle of $45^{\circ}$, will be different at different rotational speeds. For example, at $\omega=100 \%$, the peak power occurs at duty ratio $d=0.48$; whereas at $\omega=80 \%$, the peak power occurs at the duty ratio $d=0.62$. Note that for the same range of duty ratio, the output power at the rated rotational speed $\omega=100 \%$ is higher than the available output power for $\omega=80 \%$.

\section{3) $D C$ - $A C$ Inverter}

In Figure 14, the DC-AC inverter interfaces the tidal generator to the grid. The real and reactive power is controlled independently and instantaneously. The DC-AC inverter in general is controlled to provide the interaction between the tidal generator and the grid in particular to provide ridethrough capability (e.g., low-voltage ride-through, highvoltage ride-through, or fault ride-through in general) and to ensure high power quality output on the grid side. The controller must be tuned to follow the applicable local or regional grid code at the point of interconnection. In the future, it is likely that the tidal generator may be required to provide ancillary services to the grid (frequency responsee.g., droop control, inertial response, and voltage/reactive power control).

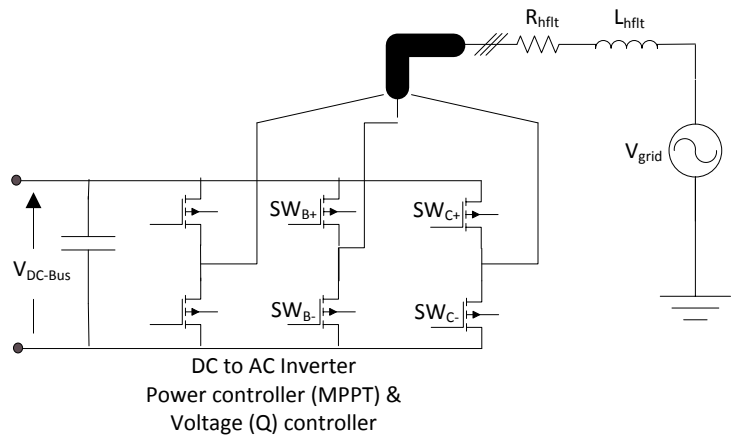

Fig. 14. Operation at variable speed and variable voltage, $V_{D C}$

\section{B. Maximum Power Point Tracking}

Many references can be found describing the method of achieving maximum power point tracking (MPPT) [9-10]. MPPT operation is an important aspect of renewable energy generation because renewable energy resources vary with time, and MPPT enables the generator to harvest the maximum amount of energy from the varying resource. MPPT has been implemented in wind generation, PV generation, and other generation systems. Several methods implemented in PV and wind generation include perturb-and-observe, hillclimbing, and passive MPPT.

\section{SUMMARY AND CONCLUSION}

This paper presented the basic operation of river and tidal generation. The similarities of the generation system to those of the wind turbine system make it possible to start the analysis by using the basic equations used to describe wind power generation. The data analysis and calculations are given per unit when possible to make the analysis as generic as 
possible and accomplish two major goals: to transport the control system to different power ratings and to make the analysis agnostic to different manufacturers; thus, no proprietary information is revealed.

- We proposed using a DC-DC boost converter to interface between the generator-diode and DC-AC inverter.

- The generator is located underwater and connected via a submarine cable carrying variable AC from the generator (at $13 \mathrm{~Hz}, \mathrm{~V}_{\mathrm{LL}}=270 \mathrm{~V}$ )

- $\quad$ A diode bridge (AC capacitor compensation $900 \mathrm{kVAR}$ ) is located onshore and connected to the submarine cable to rectify the variable $\mathrm{AC}$ from the RivGen generator. The diode bridge output is $365 \mathrm{~V}$

- A DC-DC boost converter with $\mathrm{L}=10 \mathrm{mH}$ and a DC capacitor at $\mathrm{C}=1,500 \mathrm{uF}$ and a switching frequency of 2 $\mathrm{kHz}$ are used to maintain the DC bus voltage at $800 \mathrm{~V}$ (at $13 \mathrm{~Hz}$, converting the $365 \mathrm{~V}_{\mathrm{DC}}$ diode bridge output into $800 \mathrm{~V}$ input to the DC-AC inverter).

- $\quad$ A DC-AC inverter at a switching frequency of $1.9 \mathrm{kHz}$ is controlled as the MPPT of the RivGen while converting $800 \mathrm{~V}$ into $480 \mathrm{~V}$ at $60 \mathrm{~Hz}$ into the grid.

\section{ACKNOWLEDGMENT}

This is a collaborative work between Ocean Renewable Power Company and the National Renewable Energy Laboratory (NREL), and it was supported by the U.S. Department of Energy under Contract No. DE-AC36-08GO28308 with NREL.

\section{REFERENCES}

[1] K. S. Lee and L. Y. Seng, "Preliminary Investigation of the Potential of Harnessing Tidal Energy for Electricity Generation in Malaysia," presented at the IEEE Transmission and Distribution Conference and Exposition, Chicago, IL, April 21-24, 2008.

[2] A. S. Bahaj, W. M. J. Batten, and G. McCann, "Experimental Verifications of Numerical Predictions for the Hydrodynamic Performance of Horizontal Axis Marine Current Turbines," Journal of Renewable Energy, vol. 32, pp. 2479-2490, 2007, Elsevier Ltd.

[3] A. S. Bahaj, A. F. Molland, J. R. Chaplin, and W. M. J. Batten, "Power and Thrust Measurements of Marine Current Turbines under Various Hydrodynamic Flow Conditions in a Cavitation Tunnel and a Towing Tank," Journal of Renewable Energy, vol. 32, pp. 407-426, 2007, Elsevier Ltd.

[4] Y. Li, B. J. Lence, and S. M. Calisal, "Modeling Tidal Turbine Farm with Vertical Axis Tidal Current Turbines," presented at the IEEE International Conference on Systems, Man and Cybernetics, Montreal, Quebec, Canada, Oct. 7-10, 2007.

[5] M. L. Rahman, S. Oka, and Y. Shirai, "Hybrid Power Generation System Using Offshore-Wind Turbine and Tidal Turbine for Power Fluctuation Compensation," IEEE Transactions on Sustainable Energy, vol.1, no. 2, July 2010.

[6] Y. Kyozuka and K. Ogawa, "Tidal Current Power Generation Making Use of a Bridge Pier," presented at OCEANS, May 16-19, 2007, Singapore, Graduate School of Engineering Sciences, Kyushu University.

[7] N. Kumar, S. Majumdar, and G. M. Babu, "Automatic Control of Tidal Power Plant," presented at the 2012 International Conference on Emerging Trends in Electrical Engineering and Energy Management (ICETEEEM), Chennai, India, Dec. 13-15, 2012.
[8] D. N. Deokar, N. S. Lingayat, S. A. Khaparde, and S. P. Sukhatme, "Modeling Tidal Power Plant at Saphale," presented at the IEEE Region 10 International Conference on Global Connectivity in Energy, Computer, Communication and Control, New Delhi, India, Dec. 17-19, 1998,.

[9] J. S. Choi, R. G. Jeong, J. H. Shin, C. K. Kim, and Y. S. Kim, "New Control Method of Maximum Power Point Tracking for Tidal Energy Generation System," In Proc. 2007 International Conference on Electrical Machines and Systems, Seoul, Korea, Oct. 8-11.

[10] Y. Jiang, M. F. Rong, and L. Y. Hua, "Variable Speed Constant Frequency Tidal Current Energy Generation and Control Strategy for Maximum Power Point Tracking and Grid Connection," in Proc. 2009 Sustainable Power Generation and Supply, Nanjing, China, April 6-7, 2009.

[11] E. Muljadi, "Turbine Control of Tidal and River Power Generator," presented at the North American Power Symposium (NAPS) 2016, September 2016, Denver, Colorado. 